\title{
Meningioma with Intratumoral Abscess: Review of Literature
}

\author{
Mohana Rao Patibandla $^{1 *}$, Dileep Chowdary Addagada ${ }^{2}$, Gokul Chowdary Addagada ${ }^{3}$ \\ ${ }^{1}$ Department of Neurosurgery, University of Virginia, USA \\ ${ }^{2}$ Katuri Medical College, Guntur, India \\ ${ }^{3}$ Guntur Medical college, Guntur, India
}

"Corresponding author: Mohana Rao Patibandla, Department of Neurosurgery, University of Virginia, 725 Denali Way, Apt \# 202A, Charlottesville, Virginia - 22903, USA. Tel: +12162787670; Email: drpatibandla@gmail.com

Citation: Patibandla MR, Addagada DC, Addagada GC (2017) Meningioma with Intratumoral Abscess: Review of Literature. J Surg. JSUR-159. DOI: 10.29011/JSUR-159.000059

Received Date: 01 August, 2017; Accepted Date: 21 August, 2017; Published Date: 28 August, 2017

\begin{abstract}
Intracranial intratumoral abscess formation is a very rare process, most of the previously reported cases are sellar and parasellar lesions where infection directly extends from infected sinuses. Other reported lesions involving intratumoral abscess are metastasis and glioblastoma. Meningiomas are known for their rich blood supply, their proximity to dural venous sinuses increases their propensity to seed by blood-borne metastasis. Numerous cases of metastasis within a meningioma have been reported but infectious pathology is unusual. Bacterial seeding of a meningioma with resultant intratumoral abscess formation is a rare event; here we review reported cases and provide a unique case report of deep-seated intraventricular meningioma associated with intratumoral abscess mimicking necrosis that expands the differential diagnosis of a tumor with central cavitation that clinicians should be cognizant especially in the presence of an external source of infection.
\end{abstract}

Keywords: Abscess; Intratumoral Abscess; Meningioma; Metastasis

\section{Introduction}

Intratumoral abscess is an unusual presentation specifically in intracranial tumors with exception to pituitary and parasellar lesions, where the infection commonly seeds through direct extension from sinuses. Here, we present a rare case of a meningioma with central abscess that was failed to reveal on magnetic resonance spectroscopy.

As meningiomas are in common association with large blood supply from dural arteries and association with venous sinuses, they are more prone to blood borne infiltration. Bacterial seeding of a meningioma associated with intratumoral abscess formation has been reported previously in patients with convexity meningioma but deep-seat intraventricular lesions with intratumoral abscess has not been reported and expands the differential of an enhancing cavitary mass.

\section{Case Report}

This 35-year-old woman presented to the emergency department with insidious onset, gradually progressive headache for 3 months along with 2 episodes of vomiting. A Computerized Tomography $(\mathrm{CT})$ scan performed with and without contrast revealed a hyperdense periphery with hypodense center mass lesion in the right lateral ventricle with peripheral enhancement and hyperdensity (Figure 1). 


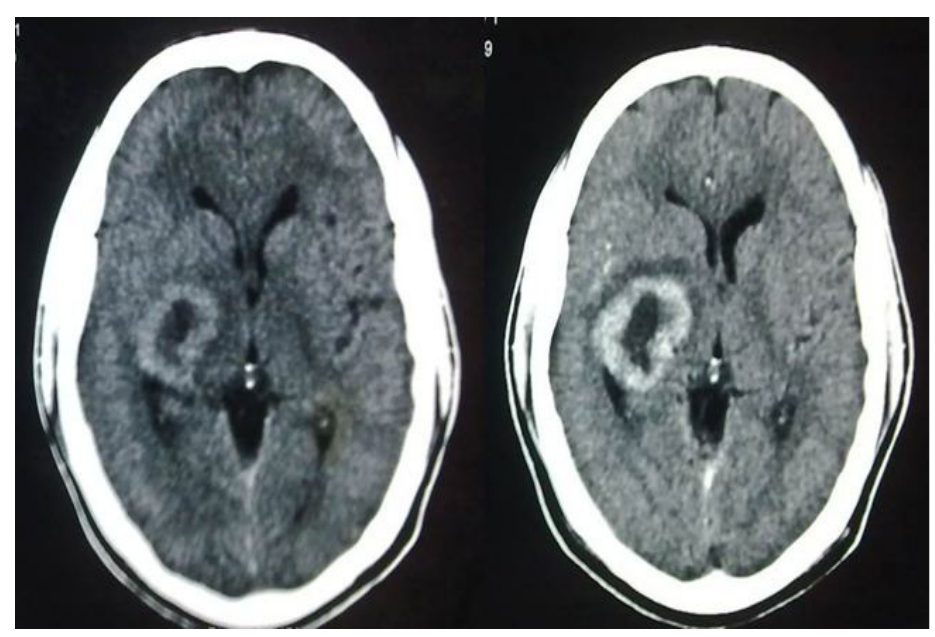

Figure 1: Computerized Tomogram plain and contrast showing hyperdense peripheral solid region which is enhancing with contrast and central non-enhancing region.

A magnetic resonance image with and without contrast showed an enhancing periphery isointense border and nonenhancing central compartment (Figure 2).

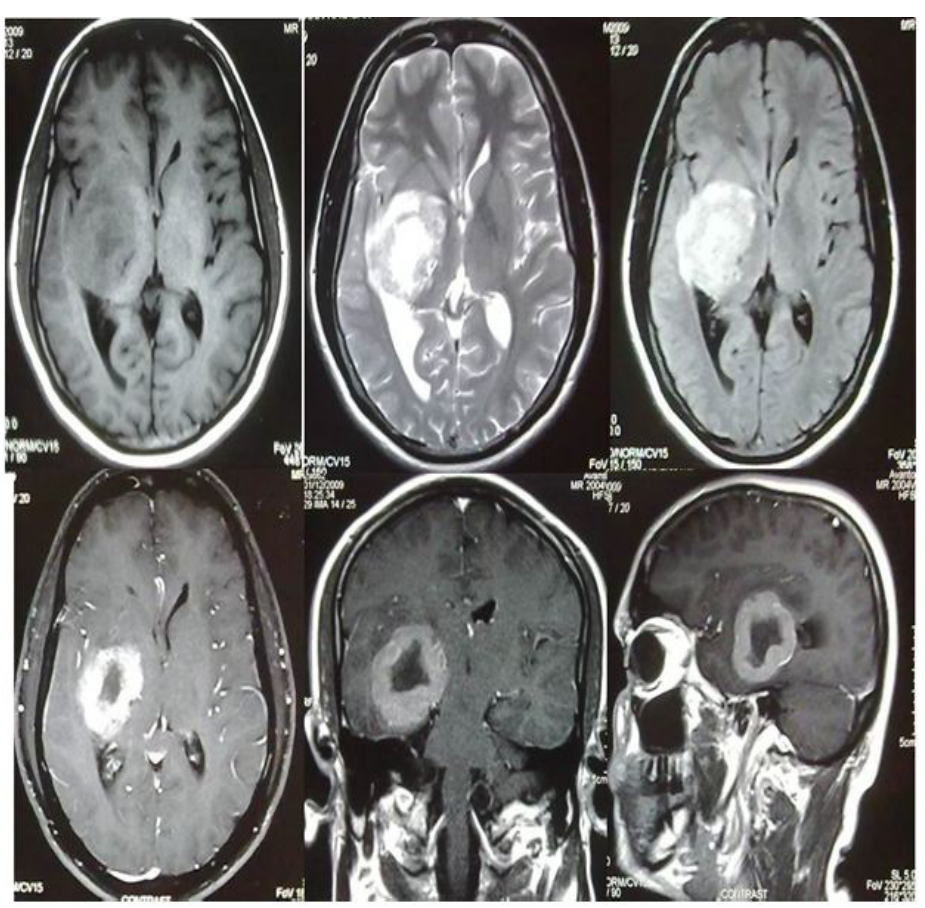

Figure 2: Magnetic Resonance Imaging plain and contrast showing solid enhancing peripheral region with central non-enhancing necrotic portion(abscess)

Magnetic Resonance Spectroscopy (MRS) (Figure 3).

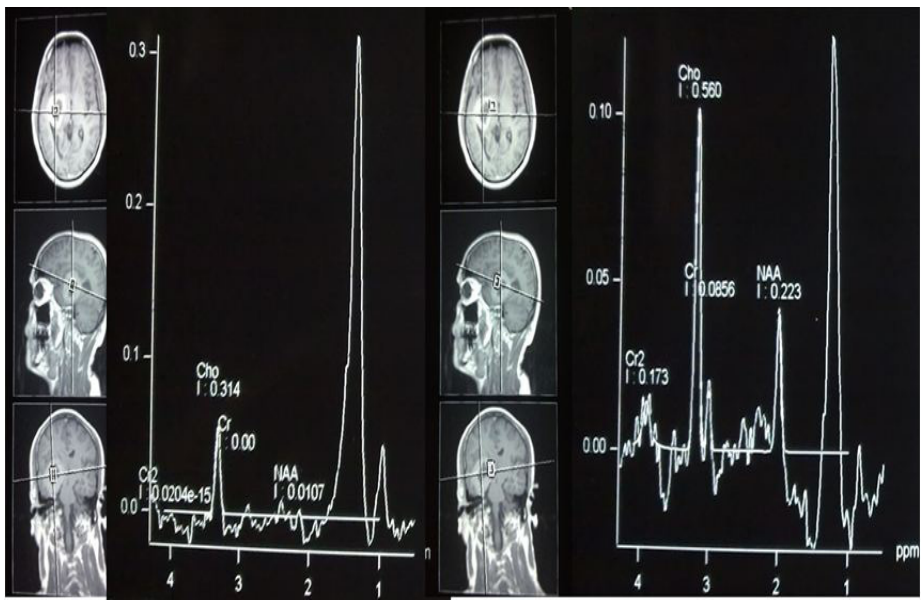

Figure 3: Magnetic resonance spectroscopy showing lacate peak with low $\mathrm{Cho} / \mathrm{Cr}$ ratio in the nonenhancing region.

Showed elevated lactate peak with reduced $\mathrm{Cho} / \mathrm{Cr}$ peak in the center of lesion, raised $\mathrm{Cho} / \mathrm{Cr}$ peaks with elevated lactate peak in the wall of the lesion, suggestive of probability of tumor with necrosis. Laboratory studies included an erythrocyte sedimentation rate and acute phase reactant $\mathrm{C}$-reactive protein was elevated with positive urine culture for Gram negative organism Proteus mirabilis. In view of radiological and laboratory findings, tumor with necrosis was included as pre-operative differential diagnosis. The patient was loaded with anti-seizure medications and surgery was done with presumed tumor removal through Right frontotemporoparietal craniotomy. Intraoperatively, we found solid peripheral portion with central cavity of yellowish pus, (Figure 4).

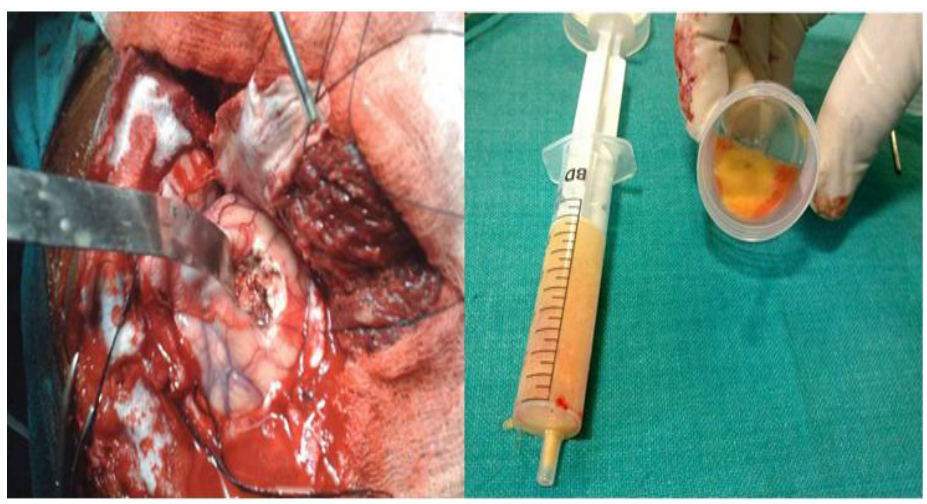

Figure 4: Specimen of abscess showing yellow colored pus and intra op meningioma.

Which we obtained for cultures of bacteria, yeast, and tuberculosis. To our surprise histopathology showed a transitional-type meningioma with central portion of the pus and inflammatory cells (Figure 5). 


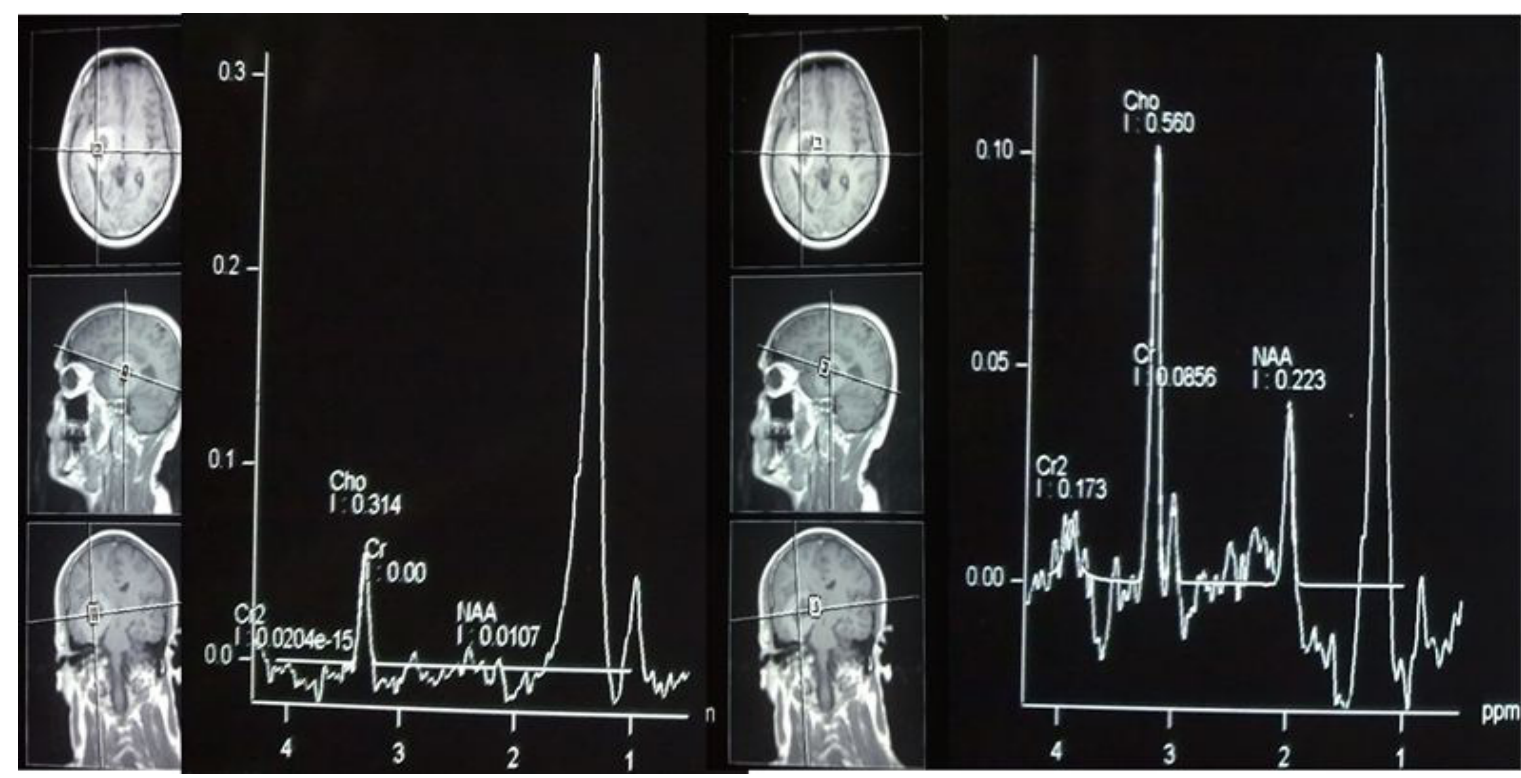

Figure 5: Histopathological exam Meningioma inner border infiltrated with inflammatory cells and Gram smear of Gram negative rods.

The cultures from the intratumoral abscess showed growth of Proteus mirabilis which was consistent with urinary tract infection. After the surgery Cefeperazone plus Sulbactum, Amikacin antibiotics were given intravenously for 6 weeks and converted to oral antibiotics for the next 3 weeks. At the end of 2 years patient was doing well with resolution and without deficits.

\section{Discussion}

Only few patients with intracranial tumors with tumor associated abscesses have been reported those include pituitary tumors, craniopharyngiomas, meningiomas, astrocytomas, glioblastomas, and ependymoma [1]. The previously reported cases of meningioma with intratumoral abscess are listed in the (Table 1).

\begin{tabular}{|c|c|c|c|c|c|}
\hline Series & Age/sex & Associated conditions & Meningioma type & pathogen & outcome \\
\hline $\begin{array}{l}\text { Shimomura, et al. } \\
1994 \text { [2] }\end{array}$ & $64 / \mathrm{F}$ & $\begin{array}{c}\text { Prolapsed uterus } \\
\text { Sepsis Bacterial men- } \\
\text { ingitis }\end{array}$ & $\begin{array}{c}\text { Transitional Parasag- } \\
\text { gital }\end{array}$ & $\begin{array}{l}\text { Blood culture: Bacteroides oralis. } \\
\text { Abscess: gram negative rods }\end{array}$ & Left hemiparesis \\
\hline $\begin{array}{c}\text { Eisenberg, et al. } 1998 \\
{[3]}\end{array}$ & $78 / \mathrm{F}$ & Urinary tract infection & $\begin{array}{l}\text { Transitional paras- } \\
\text { agittal }\end{array}$ & $\begin{array}{l}\text { Urinary tract: Proteus mirabilis } \\
\text { Abscess: Proteus mirabilis }\end{array}$ & $\begin{array}{l}\text { Deep venous throm- } \\
\text { bosis with placement } \\
\text { of inferior vena cava } \\
\text { filter }\end{array}$ \\
\hline Nassar, et al. 1997 [4] & $35 / \mathrm{F}$ & Urinary tract infection & $\begin{array}{l}\text { Falcotentorial occipi- } \\
\text { tal meningioma }\end{array}$ & E. coli & Favorable \\
\hline Yeates, et al. 2003 [5] & $38 / \mathrm{F}$ & $\begin{array}{l}\text { Genito-Urinary } \\
\text { surgery }\end{array}$ & $\begin{array}{l}\text { Lt Convexity Menin- } \\
\text { gioma }\end{array}$ & Bacteroides fragilis & Favorable \\
\hline Young, et al. 2005 [6] & $38 / \mathrm{M}$ & Dental surgery & $\begin{array}{l}\text { Right temporal pole } \\
\text { meningioma }\end{array}$ & $\begin{array}{c}\text { Group B Streptococcus, Pepto- } \\
\text { streptococcus }\end{array}$ & Favorable \\
\hline Lind, et al. 2005 [7] & $74 / F$ & Atrial Fibrillation & $\begin{array}{l}\text { Lt Parasagittal menin- } \\
\text { gioma }\end{array}$ & Citrobacter koseri & Favorable \\
\hline $\begin{array}{c}\text { Onopchenko, et al. } \\
1999[8]\end{array}$ & $63 / \mathrm{F}$ & $\begin{array}{c}\text { Pyonephrosis Gluteal } \\
\text { abscess }\end{array}$ & $\begin{array}{l}\text { Frontotemporal con- } \\
\text { vexity meningioma }\end{array}$ & Staphylococcus & Favorable \\
\hline Lo WB [9] & $70 / \mathrm{M}$ & Lithotripsy & $\begin{array}{l}\text { Rt Parietal and tempo- } \\
\text { ral meningiomas }\end{array}$ & E. coli & Favorable \\
\hline Krishnan SS [10] & $55 / \mathrm{F}$ & DJ stent & $\begin{array}{l}\text { Lt posterior frontal } \\
\text { meningioma }\end{array}$ & E. coli & Favorable \\
\hline
\end{tabular}


Citation: Patibandla MR, Addagada DC, Addagada GC (2017) Meningioma with Intratumoral Abscess: Review of Literature. J Surg. JSUR-159.

\begin{tabular}{|c|c|c|c|c|c|}
\hline Present case, 2014 & $35 / \mathrm{M}$ & Urinary tract infection & $\begin{array}{c}\text { Lateral ventricle tran- } \\
\text { sitional meningioma }\end{array}$ & $\begin{array}{c}\text { Proteus mirabilis } \\
\text { of 2 years }\end{array}$ \\
\hline
\end{tabular}

Table 1: Previously reported cases in the literature.

[2-10] This is a unique case report, in the sense previously reported cases are within convexity meningiomas where as we report a deep-seated intraventricular lesion Magnetic resonance spectroscopy findings of elevated lactate peak in the abscess with raised alanine peak in the solid portion of the tumor are suggestive of meningioma with abscess formation, but those findings were not seen. Diffusion Weighted Imaging (DWI) with Apparent Diffusion Coefficient (ADC) maps typically would provide better diagnosis of abscess along with spectroscopy, but in our case, the diffusion weighted imaging was not available for review.

Meningiomas have a rich blood supply depending on the location from either the internal or external carotid artery or its branches with drainage to into surrounding dural venous sinuses. The etiology, in our case, leading to the intratumoral abscess formation begins with a transient bacteremia from a urinary tract infection that hematogenously seeded the existing meningioma tumor as a result of its rich blood supply and relationship with the choroid plexus. Intracerebral tumors are more vulnerable to infective embolization due to presence of necrosis, arteriovenous shunts, hematoma, poor oxygenation and disrupted blood brain barrier [1]. Several predisposing factors which make meningioma a favorable site for abscess formation include: Very high tumoral vascularity, lack of blood brain barrier, highly vascular channels may act as filter to retain bacteria, non-branching arterial supply network until it reaches the center of meningioma, absence of immune response, and presence of lipids and glycoproteins which lead to rich nutritive environment [10]. Histopathological features in these lesions include well defined tumour with necrotic centre and a demarcation interface of abscess from tumor. There is perivascular and intratumoural infiltration by polymorphs and microbial colonies; the latter are sufficient enough to be cultured. These criteria are mandatory to establish a diagnosis of purulent tumourn [11]. Common source of the abscess in the setting of tumor are paranasal sinuses, the noncontiguous sources reported in literature are related to genitourinary surgery, dental surgery, septic state and some cardiac-related seeding. [2-9] Causative organisms in the literature are E. coli, Proteus mirabilis, Staphylococcus, Bacteroides fragilis/oralis, Citrobacter koseri and Group B Streptococcus [2-10].
We propose intratumoral abscess should be considered as one of the differential diagnosis in patients who present with tumors with non-enhancing central cavity with concomitant state of infection and/or source of infection. Treatment should include removal of the tumor with abscess along with both intravenous antibiotics for a period of 6 weeks with the monitoring of inflammatory markers. Most of the patients reported in literature have good prognosis.

\section{References}

1. Bansal S, Pathak A, Jindal VN, Khosla VK, Banerjee AK, et al. (2001) Cerebral abscess with astrocytoma. Neurol India 49: 91.

2. Shimomura T HS, Kasai N, Tsuruta K, Okada H (1994) Meningioma associated with intratumoral abscess formation: Case report. Neurol Med Chir (Tokyo) 34: 440-443.

3. Eisenberg MB LR and Stanek AE (1998) Abscess formation within a parasagittal meningioma. Case report. Journal of neurosurgery 88: 895-897.

4. Nassar SI, Haddad FS, Hanbali FS, Kanaan NV (1997) Abscess superimposed on brain tumor: Two case reports and review of the literature. Surg Neurol 47: 484-488.

5. Yeates KE, Halliday W, Miyasaki J, Vellend H, Straus S (2003) A case of 'circling seizures' and an intratumoral abscess. Clin Neurol Neurosurg 105: 128-131.

6. Young JP and Young PH (2005) Meningioma associated with abscess formation: A case report. Surg Neurol 63: 584-585.

7. Lind CR, Muthiah K, Bok AP (2005) Peritumoral Citrobacter koseri abscess associated with parasagittal meningioma. Neurosurgery 57: E814.

8. Onopchenko EV and Grigorian luA (1999) Meningioma with a peritumoral abscess. Zh Vopr Neirokhir Im N N Burdenko 1: 28-30.

9. Lo WB, Cahill J, Carey M, Mehta H, Shad A (2014) Infected intracranial meningiomas. World Neurosurg 81: e9-13.

10. Krishnan SS, Panigrahi M, Pattanagare SG, Varma RD, Rao SI (2014) Abscess within a meningioma: pathogenesis and rare case report. Neurol India 62: 196-198.

11. Hasearts R RJ (1963) Le problemie les tumers cerebrates abcedees. Acta Neurological et Psychiatrica Belgica 63: 1013-1022. 